\title{
Experimental and modeling studies on microwave-assisted extraction of mangiferin from Curcuma amada
}

\author{
Jeke Kullu • Abhishek Dutta • Denis Constales • \\ Surabhi Chaudhuri $\cdot$ Debjani Dutta
}

Received: 28 November 2012/ Accepted: 18 February 2013/Published online: 21 April 2013

(C) The Author(s) 2013. This article is published with open access at Springerlink.com

\begin{abstract}
Mangiferin, a bioactive compound having potent nutraceutical, strong antioxidant and pharmacological significance has been extracted using microwaveassisted extraction (MAE) technique from Curcuma amada, commonly known as mango ginger. The extraction solvent ethanol is eco-friendly, nontoxic and reduces the risk of environmental hazards. The influence of several independent variables such as microwave power, ethanol concentration, extraction (irradiation) time and pre-leaching time has been studied under varying conditions using one-factor-at-a-time analysis to obtain an optimal extraction ratio. The maximum mangiferin content of $1.1156 \mathrm{mg} /$ $\mathrm{g}$ is obtained at microwave power of $550 \mathrm{~W}$ and extraction time of $50 \mathrm{~s}$ with $80 \%$ ethanol as a solvent and preleaching time of $20 \mathrm{~min}$. The results indicate that microwave power and ethanol concentration have the most significant effect on the yield of mangiferin content. The presence of mangiferin in final Curcuma amada extract is confirmed through high-performance liquid chromatography and the functional groups are identified through Fourier transform infrared spectroscopy analyses using standard mangiferin. The experimental profiles are fitted
\end{abstract}

J. Kullu $\cdot$ S. Chaudhuri $\cdot$ D. Dutta $(\bowtie)$

Department of Biotechnology, National Institute of Technology, Durgapur 713209, India

e-mail: debs_2000in@yahoo.com; debjani.dutta@bt.nitdgp.ac.in

A. Dutta

Department of Chemical Engineering, Groep T-Leuven

Engineering College (Associatie KU Leuven),

A. Vesaliusstraat 13, 3000 Leuven, Belgium

D. Constales

Vakgroep Wiskundige Analyse, Ghent University, Galglaan 2, Blok S22, 9000 Ghent, Belgium into a two-parameter modified first-order kinetic model and a three-parameter modified logistic model and checked using the goodness-of-fit criterion. The Curcuma amada retained its antioxidant activity after MAE treatment and the antioxidant activity of mangiferin obtained after extraction using DPPH free radical scavenging assay is studied.

Keywords Microwave-assisted extraction - Mangiferin · Antioxidant activity $\cdot$ ANOVA $\cdot$ Mathematical modeling

$\begin{array}{ll}\text { Abbreviations } \\ \text { ANOVA } & \text { Analysis of variations } \\ \text { MAE } & \text { Microwave-assisted extraction } \\ \text { OFAT } & \text { One-factor-at-a-time } \\ \text { HPLC } & \text { High performance liquid chromatography } \\ \text { FTIR } & \text { Fourier transform infrared spectroscopy } \\ \text { SCFE } & \text { Supercritical fluid extraction } \\ \text { UAE } & \text { Ultrasound assisted extraction } \\ \text { HRE } & \text { Heat reflux extraction }\end{array}$

Introduction

Traditional plant spices, similar to fruits and vegetables, are known to contain health-promoting components such as vitamins, minerals, antioxidants and prebiotics (Omenn et al. 1996). In particular, plant spices are used in foods because they impart desirable flavours and may fulfil more than the one function for which they are added. Extensive research is being conducted on traditional medicines, on different plant species and their therapeutic applications all over the world. Curcuma amada, commonly known as mango ginger, is an important member of the 
Zingiberaceae family. It has an Indo-Malayan origin and is distributed widely in the tropics from Asia to Africa and Australia (Sasikumar 2005). Curcuma amada is named mango ginger because it is morphologically similar to ginger and imparts a mango flavour and is typically used in the manufacture of pickles, culinary preparations and salads for flavour, candy and sauce (Shankaracharya 1982). Curcuma amada has pharmacological significance for a variety of ailments. Therapeutically, mango ginger is used to treat a range of mood and medical disorders in traditional and ayurvedic medicine. Curcuma amada is credited with diverse bioactive molecules demonstrating antibacterial, antifungal, anti-inflammatory, anti-hypercholesterolemic, insecticidal, aphrodisiac, antipyretic and antioxidant properties (Singh et al. 2010). Mangiferin is an important bioactive constituent of mango ginger containing xanthone-C-glycoside, which has numerous pharmacological properties and is an important phytochemical. It has antidiabetic, cardioprotective, immunomodulatory, antioxidant, antitumour, hepatoprotective and vasorelaxant properties and is useful in the treatment of biliousness, skin diseases, bronchitis, asthma and inflammation (Jatoi et al. 2007). Extraction forms the first basic step in medicinal plant research because the preparation of crude extracts from plants is the starting point for the isolation and purification of chemical constituents (Romanik et al. 2007). Keeping in mind the requirements such as shortened extraction time, reduced solvent consumption, increased pollution prevention and the special care needed for thermolabile constituents, numerous extraction techniques have been developed for the purpose of obtaining pharmacologically active compounds from various plant sources such as supercritical fluid extraction (SCFE), microwave-assisted extraction (MAE), ultrasound-assisted extraction (UAE) and heat reflux extraction (HRE). However, because of several disadvantages with the traditional extraction techniques like sonication and Soxhlet extraction, non-conventional extraction techniques like SCFE, extraction by microwave and ultrasound sources have gained importance. The use of microwaves in analytical sciences is not new; the first reported analytical use for microwave oven was in 1986 for the extraction of organic compound (Dean 2010). In recent years, MAE has attracted growing interest as it allows rapid extraction of solutes from solid matrices, with extraction efficiency comparable to that of the classical techniques (Camel 2000). Heating occurs in a targeted and selective manner in MAE with practically no heat being lost to the environment, and the mechanism can significantly reduce the extraction time (Huie 2002). This means it requires less solvent volume and is thus time conserving with improved product recovery. Further, the extraction solvent used is usually water or ethanol, which is inexpensive, nontoxic and environmentally benign (Ferguson et al. 2012). Samples pretreated with solvents with higher microwave absorbing capacity when coupled with extracting solvents like ethanol bring about heating by at least two competing mechanisms, namely direct heating from the interaction of microwaves with ethanol and heating from the diffusion of excess heat resulting from the interaction of the microwaves with the pretreated matrix (Mandal et al. 2007). In our previous study (Padmapriya et al. 2012), MAE of mangiferin from Curcuma amada was studied using only two independent factors, namely microwave power and extraction (irradiation) time. However, it has been observed that several other extraction variables such as solvent concentration, ethanol concentration and preleaching time could also be influential factors in the optimization of the extraction protocol of a bioactive compound, which may act dependently or independently (Dhobi et al. 2009). In the present study, therefore, a more rigorous approach has been applied to understand the influence of these independent factors on mangiferin extraction using mathematical modeling. The presence of mangiferin in final Curcuma amada extract was confirmed using high-performance liquid chromatography (HPLC) using standard mangiferin and was further subjected to Fourier transform infrared spectroscopy (FTIR) analysis for identification of the functional groups. The antioxidant activity of mangiferin obtained after extraction using DPPH free radical scavenging assay has also been studied.

\section{Materials and methods}

\section{Plant material}

Fresh and healthy Curcuma amada (mango ginger) were purchased from the local market in Durgapur, West Bengal. The rhizomes were washed, peeled and cut into fine pieces and then dried in a hot-air oven (OVFU) at $70{ }^{\circ} \mathrm{C}$ until constant weight and was well blended. Mangiferin standard was purchased from Sigma-Aldrich, USA.

\section{Microwave-assisted extraction (MAE)}

Microwave-assisted extraction was performed using a microwave apparatus (Samsung Trio, Model CE117ADV; $230 \mathrm{~V} \sim 50 \mathrm{~Hz})$ in a closed vessel system. $2.5 \mathrm{~g}$ of dried Curcuma amada powder was extracted with $25 \mathrm{ml}$ solvent under different MAE conditions. After extraction, the vessels were allowed to cool at room temperature before opening. Microwave power $(250,350,450,500,550$ and $900 \mathrm{~W})$, ethanol concentration $(50-100 \%, \mathrm{v} / \mathrm{v})$, extraction time (1-120 s, with an interval of $5 \mathrm{~s})$ and pre-leaching time (1-30 $\mathrm{min}$, with an interval of $5 \mathrm{~min}$ ) were evaluated 
for the extraction of mangiferin from Curcuma amada. The extraction of mangiferin was carried out using the method of Padmapriya et al. (2012). The final extract was evaporated and dissolved in DMSO before UV-vis spectrophotometric (Techcomp, UV 2310) analysis. For the estimation of mangiferin, the method described by Joubert et al. (2008) was used and the absorbance was measured at $410 \mathrm{~nm}$.

High-performance liquid chromatography (HPLC) analysis

The final extract of Curcuma amada was analysed by HPLC (Waters 600) equipped with a UV-vis detector (Waters 2489) according to the method described by Muruganandan et al. (2002). Chromatographic separation was performed on a reverse-phase column (C18, $4.6 \times 250 \mathrm{~mm}$, Waters) with the temperature of the column being maintained at $25^{\circ} \mathrm{C}$. The mobile phase was acetonitrile and $3 \%$ acetic acid in the ratio 16:84 at a flow rate of $0.5 \mathrm{ml} / \mathrm{min}$. The sample injection volume was $10 \mu \mathrm{l}$. The peaks were evaluated based on their absorbance at $254 \mathrm{~nm}$. Retention time and concentration of the samples were compared with pure standard of mangiferin (SigmaAldrich, USA).

Fourier transform infrared spectroscopy (FTIR) analysis

The mangiferin extracted after MAE at $550 \mathrm{~W}$ was further subjected to FTIR analysis for identification of the functional groups. Comparing the functional groups present in standard mangiferin, the damaged functional group of the extracted mangiferin can be identified. A known weight of the final sample extract was mixed with potassium bromide and loaded onto a Perkin Elmer instrument. The samples were scanned in model spectrum-100 system in range of $400-4,000 \mathrm{~cm}^{-1}$. The spectral data obtained were compared with a standard mangiferin chart to identify the functional groups present in the sample.

\section{DPPH radical scavenging activity}

The DPPH assay was carried out according to the method reported by Ara and Nur (2009). DPPH solution (0.004\% w/v) was prepared in $95 \%$ methanol. The stock solution was diluted to final concentration of 1, 5, 10, 20, 40, 60, 80 and $100 \mu \mathrm{g} / \mathrm{ml}$. The freshly prepared DPPH solution was added in each of the test tubes containing the final concentrations of Curcuma amada methanolic extract, and after $10 \mathrm{~min}$ of incubation the absorbance was taken at $517 \mathrm{~nm}$ using a spectrophotometer. The scavenging effect
(\%) of DPPH free radical was measured using the following equation:

$$
\begin{aligned}
& \text { DPPH radical-inhibition scavenging effect }(\%) \\
& =[(\text { absorbance of control }- \text { absorbance of test sample }) / \\
& \\
& \quad(\text { absorbance of control })] \times 100 .
\end{aligned}
$$

Statistical analysis

The screening of the variables has been done using onefactor-at-a-time (OFAT) analysis, which has several advantages such as run size economy, fewer level changes and providing protection against the risk of premature termination of experiments $(\mathrm{Qu}$ and $\mathrm{Wu} 2005)$. It must be noted that although processes are commonly optimized in most industrial experiments using OFAT design approach, optimal conditions or interactions between variables cannot be predicted with this methodology (Wardhani et al. 2010). However, OFAT design allows to find out more rapidly whether a factor has any effect and is therefore a sequential learning process (Morgan and Deming 1974). The statistical software Graphpad Prism v5.0.0.2 was used for the data analysis. A two-way analysis of variance (ANOVA) was implemented to calculate the significance of the differences in the content of mangiferin. Means and coefficients of variance were computed for all qualitative analysis and treatments with homogeneous means ranked using the Newman-Keuls post hoc test. The significance of the results was established at values greater than 0.05 in all the experiments performed. The parameters of the empirical models were fitted with a nonlinear least-squares (NLLS) MarquardtLevenberg algorithm, using the device-independent plotting program Gnuplot.

\section{Mathematical modeling of mangiferin extraction}

Kinetics of MAE of mangiferin is performed at the experimental design points for the three independent variables namely, microwave power, ethanol concentration and pre-leaching time. In all these cases, the experimental data seem to follow a sigmoidal curve for which a two-parameter modified first-order kinetic model (Wardhani et al. 2010) and a three-parameter delayed logistic model with a final asymptote (Yukalov et al. 2009) are chosen to describe the evolution of microwave-assisted mangiferin extraction given as follows:

$Y=Y_{\max }\left(1-e^{-k_{\mathrm{m}} \cdot t}\right)$,

and

$Y=Y_{\max } /\left(1+e^{-k_{\mathrm{m}}(t-\tau)}\right)$, 
Fig. 1 a HPLC chromatogram of mangiferin standard. b HPLC chromatogram of mangiferin extracted from Curcuma amada by microwave-assisted extraction (MAE)
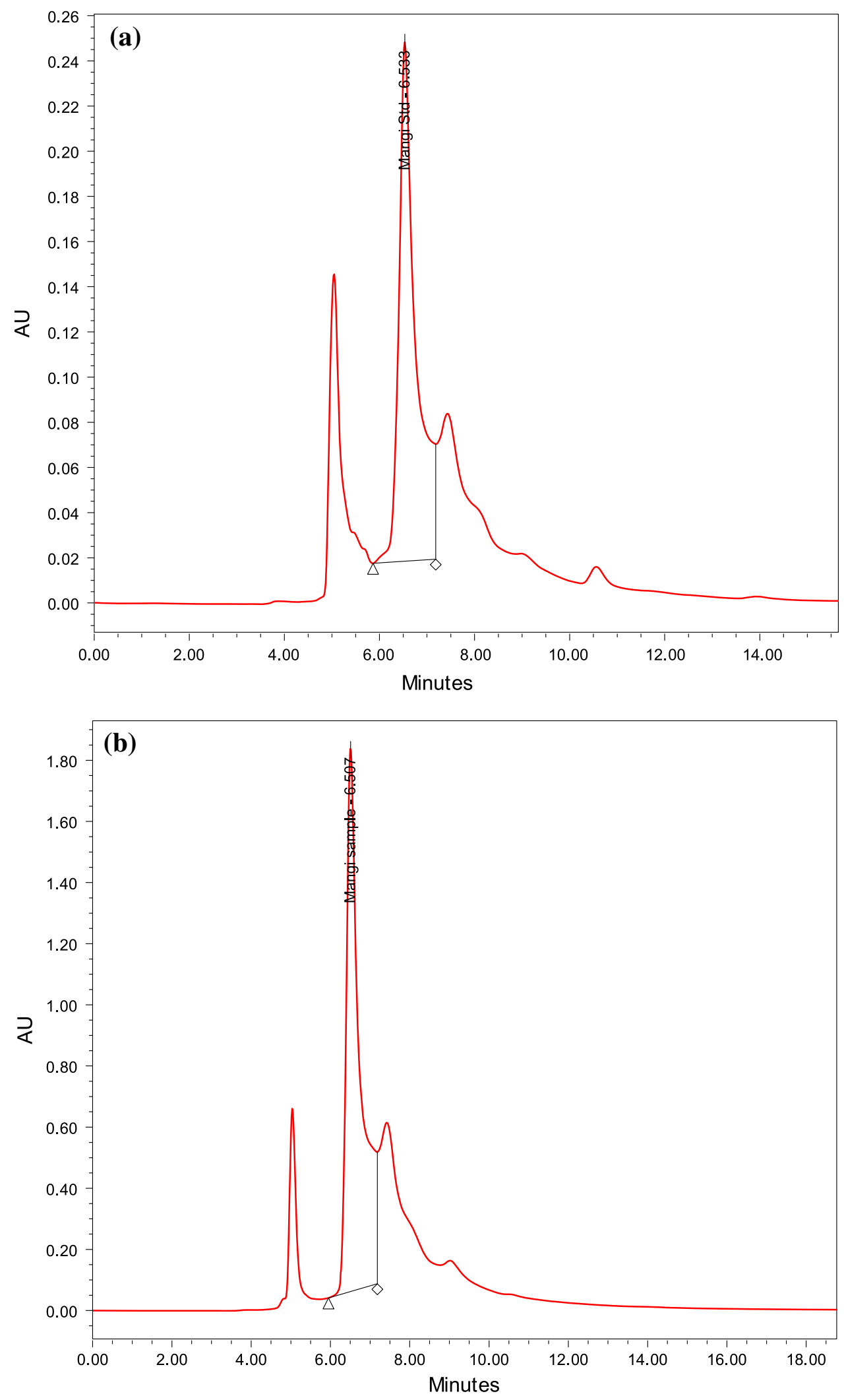

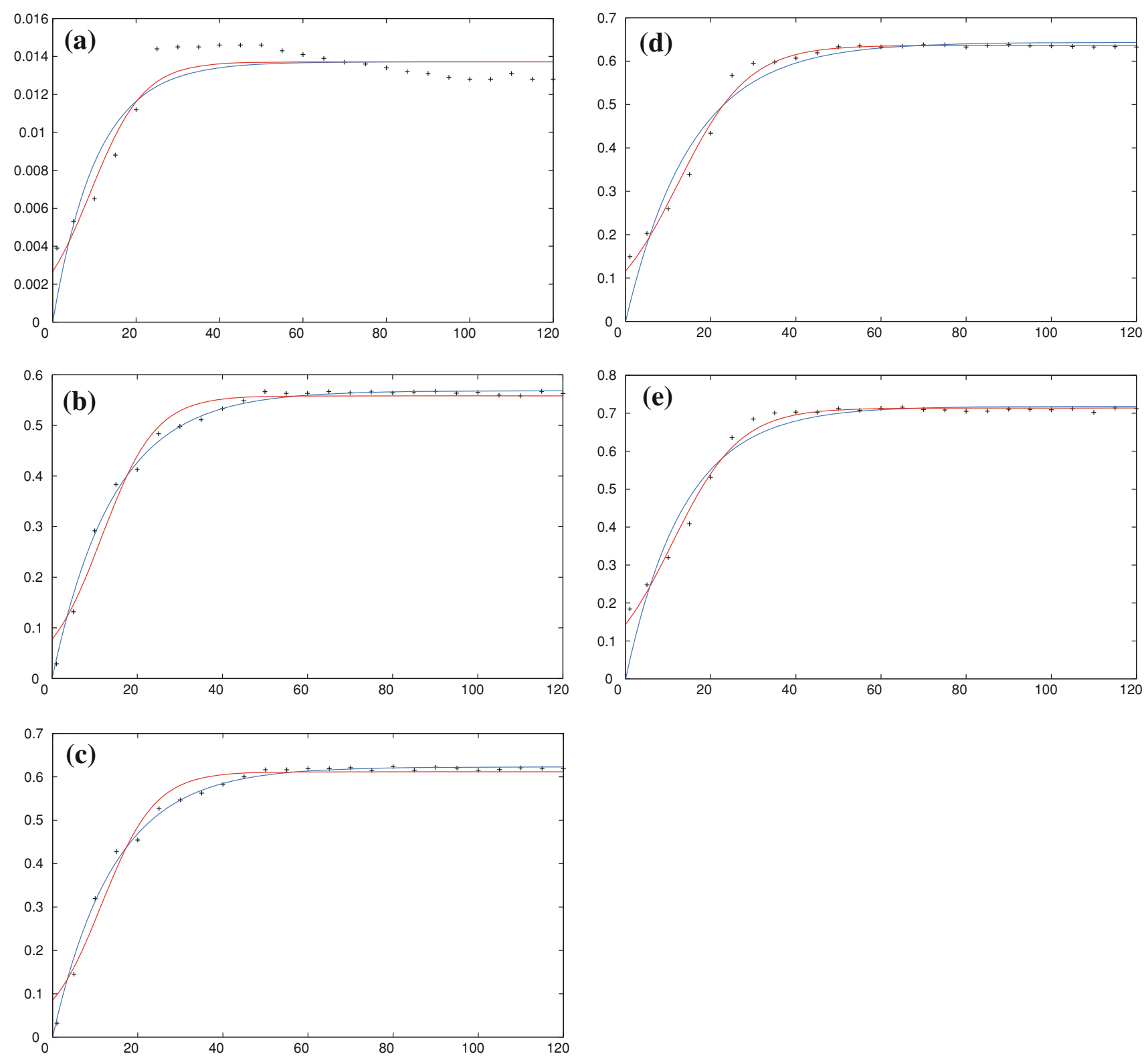

Fig. 2 Temporal evolution of the effect of microwave power (as an independent variable) on the yield of mangiferin content extracted from Curcuma amada at various experimental design points ( $x$ axis: time in $\mathrm{s} ; y$ axis: yield in $\mathrm{mg} / \mathrm{g}$ ). The experimental data (symbols)

where $Y$ is the mangiferin content $(\mathrm{mg} / \mathrm{g})$ at time $t, Y_{\max }$ is the maximum mangiferin content $(\mathrm{mg} / \mathrm{g})$ when time approaches infinity, $k_{\mathrm{m}}$ is the first-order mangiferin extraction constant or the specific rate of mangiferin concentration $\left(\mathrm{s}^{-1}\right)$ and $\tau$ is the time delay (s); else the value at $t=0$ would always be half the value at $t=\infty$ (and there is no sufficient reason to assume such a restriction).

A generalized expression to describe the dependency of both microwave power $(P)$ and ethanol concentration $(E)$ on extraction time can be written using a slightly modified delayed logistic model as follows:

fitted to the 2-parameter model (Eq. 1, blue) and 3-parameter logistic model (Eq. 2, red) are shown in Fig. 2a-e for 250, 350, 450, 500 and $550 \mathrm{~W}$, respectively

$Y=\frac{Y_{\max }\left(1+\frac{P(\text { or } E)}{P_{\text {ref }}\left(\mathrm{or} E_{\text {ref }}\right)}\right)}{1+e^{-k_{\mathrm{m}}(t-\tau)}}$

where $P_{\text {ref }}\left(\right.$ or $\left.E_{\text {ref }}\right)$ is the parameter related to microwave power (or ethanol concentration), respectively, and where the mangiferin yield $Y$ is twice the initial value.

It is important to clarify that the extraction process is the result of an interaction between Curcuma amada (mangiferin) and ethanol, causing the kinetic dependence to be of the second order. During extraction, concentration of mangiferin (solute) increases and goes to saturation 
Table 1 Test of between-subjects effects: a two-way analysis of variance with microwave power and extraction time as independent factors

\begin{tabular}{|c|c|c|c|c|c|c|c|c|}
\hline Source & & $\begin{array}{l}\text { Type III sum } \\
\text { of squares }\end{array}$ & $d f$ & Mean square & $F$ & Sig. & $\begin{array}{l}\text { Noncent. } \\
\text { parameter }\end{array}$ & $\begin{array}{l}\text { Observed } \\
\text { power }^{\mathrm{a}}\end{array}$ \\
\hline \multirow[t]{2}{*}{ Microwave power } & \multirow[t]{2}{*}{ Hypothesis error } & 10.067 & 5 & 2.013 & \multirow[t]{2}{*}{316.937} & \multirow[t]{2}{*}{0.0} & \multirow[t]{2}{*}{$1,584.685$} & \multirow[t]{2}{*}{1.0} \\
\hline & & 0.762 & 120 & $6.353 \mathrm{E}-03^{\mathrm{b}}$ & & & & \\
\hline \multirow[t]{2}{*}{ Extraction time } & \multirow[t]{2}{*}{ Hypothesis error } & 1.464 & 24 & $6.101 \mathrm{E}-02$ & \multirow[t]{2}{*}{9.604} & \multirow[t]{2}{*}{0.0} & \multirow[t]{2}{*}{230.504} & \multirow[t]{2}{*}{1.0} \\
\hline & & 0.762 & 120 & $6.353 \mathrm{E}-03^{\mathrm{b}}$ & & & & \\
\hline \multirow[t]{2}{*}{ Microwave power $\times$ extraction time } & \multirow[t]{2}{*}{ Hypothesis error } & 20.906 & 1 & 20.906 & \multirow[t]{2}{*}{342.642} & \multirow[t]{2}{*}{0.0} & \multirow[t]{2}{*}{342.642} & \multirow[t]{2}{*}{1.0} \\
\hline & & 1.464 & 24 & $6.101 \mathrm{E}-02^{\mathrm{c}}$ & & & & \\
\hline
\end{tabular}

Dependent variable: concentration of extracted mangiferin

${ }^{\text {a }}$ Computed using alpha $=0.05$

b MS (Error)

${ }^{\mathrm{c}}$ MS (TMIN)

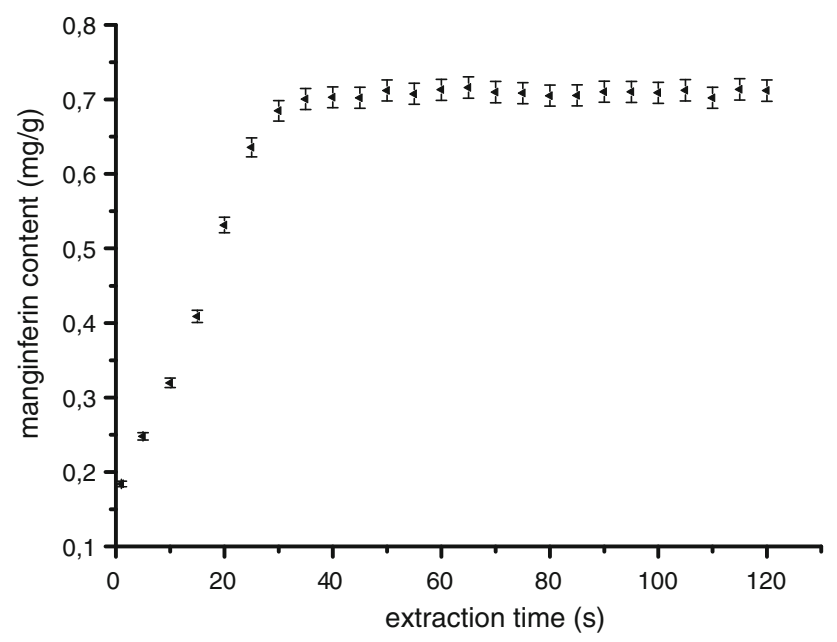

Fig. 3 Influence of extraction time on the yield of mangiferin content. Extraction condition: pre-leaching time-1 min, microwave power-550 W and ethanol concentration-100\%. The results are expressed as means of yield $\pm \mathrm{SD}$

although it is not yet extracted. However, if excess ethanol (solvent) is added to the solution, the extraction of mangiferin occurs. This reduces the apparent kinetic dependence from a second-order rate equation to a pseudo-first order rate equation (see Eqs. 1, 2).

\section{Results and discussions}

Figure 1a, b shows the chromatographic profile of the mangiferin from Curcuma amada after MAE and standard mangiferin, respectively. The retention time of $6.51 \mathrm{~min}$ obtained from the extract agreed well with the standard verifying the presence of mangiferin in Curcuma amada extract.
Effect of microwave power

Figure $2 \mathrm{a}-\mathrm{e}$ shows the effect of microwave power on mangiferin content with extraction time; the symbols represent the experimental data while the continuous curves represent the model fit. It can be clearly seen in these figures that there is a steady increase in mangiferin content up to $50 \mathrm{~s}$ at the power range from 250 to $550 \mathrm{~W}$ after which it reaches a threshold value. However, at $900 \mathrm{~W}$ there is a significant decrease in the mangiferin content and the yield decreases drastically, as was observed by the response at $900 \mathrm{~W}$ (not shown). This is in accordance with the observations of our previous study (Padmapriya et al. 2012) where a similar response was obtained for $600 \mathrm{~W}$. The mangiferin content of Curcuma amada in the control sample, i.e. before MAE, was $0.0046 \mathrm{mg} / \mathrm{g}$. The mangiferin content at 250 and $550 \mathrm{~W}$ after $50 \mathrm{~s}$ of microwave extraction is found to be 0.0146 and $0.7161 \mathrm{mg} / \mathrm{g}$, respectively. This manifold increase in mangiferin content is maximum (more than 150 times higher than the control sample) at $550 \mathrm{~W}$ after $50 \mathrm{~s}$ of extraction compared with $250 \mathrm{~W}$ (around three times higher than the control sample) for the same extraction time. This accelerated extraction of mangiferin by increasing microwave power can be correlated to the direct effects of microwave energy on molecules by ionic conduction and dipole rotation which result in power dissipated in volumetric basis inside the solvent and plant material which generate molecular movement and heating. Microwave irradiation energy disrupts the bonds because of microwave-induced dipole rotation of molecules and migration of dissolved ions. Microwave irradiation energy can enhance the penetration of solvent into the matrix and deliver efficiently to materials through molecular interaction with the electromagnetic field and thus offer a rapid transfer of energy to the solvent and 

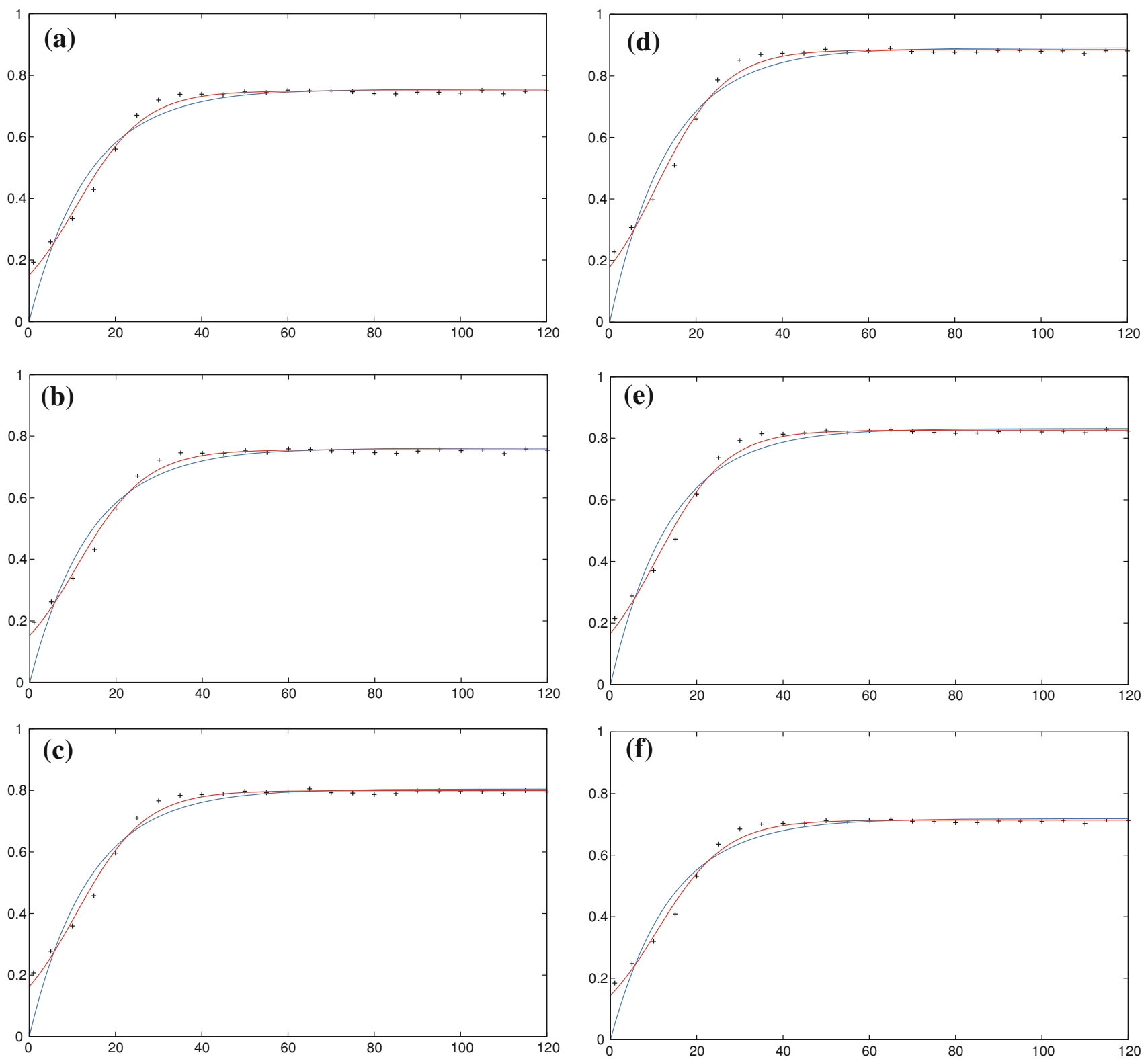

Fig. 4 Temporal evolution of the effect of ethanol concentration (as an independent variable) on the yield of mangiferin content extracted from Curcuma amada at various experimental design points ( $x$ axis: time in $\mathrm{s}$;

$y$ axis: yield in $\mathrm{mg} / \mathrm{g}$ ). The experimental data (symbols) fitted to the 2-parameter model (Eq. 1, blue) and 3-parameter logistic model (Eq. 2, red) are shown in Fig. 4a-f for 50, 60, 70, 80, 90 and $100 \%$, respectively

Table 2 Test of between-subjects effects: a two-way analysis of variance with ethanol concentration and extraction time as independent factors

\begin{tabular}{|c|c|c|c|c|c|c|c|c|}
\hline Source & & $\begin{array}{l}\text { Type III sum } \\
\text { of squares }\end{array}$ & $d f$ & Mean square & $F$ & Sig. & $\begin{array}{l}\text { Noncent. } \\
\text { parameter }\end{array}$ & $\begin{array}{l}\text { Observed } \\
\text { power }^{\mathrm{a}}\end{array}$ \\
\hline \multirow[t]{2}{*}{ Ethanol conc. } & \multirow[t]{2}{*}{ Hypothesis error } & 0.373 & 5 & $7.455 \mathrm{E}-02$ & \multirow[t]{2}{*}{392.693} & \multirow[t]{2}{*}{0.0} & \multirow[t]{2}{*}{$1,963.466$} & \multirow[t]{2}{*}{1.0} \\
\hline & & $2.278 \mathrm{E}-02$ & 120 & $1.898 \mathrm{E}-04^{\mathrm{b}}$ & & & & \\
\hline \multirow[t]{2}{*}{ Extraction time } & \multirow[t]{2}{*}{ Hypothesis error } & 4.499 & 24 & 0.187 & \multirow[t]{2}{*}{987.452} & \multirow[t]{2}{*}{0.0} & \multirow[t]{2}{*}{$23,698.838$} & \multirow[t]{2}{*}{1.0} \\
\hline & & $2.278 \mathrm{E}-02$ & 120 & $1.898 \mathrm{E}-04^{\mathrm{b}}$ & & & & \\
\hline \multirow[t]{2}{*}{ Ethanol conc. $\times$ extraction time } & \multirow[t]{2}{*}{ Hypothesis error } & 72.827 & 1 & 72.827 & \multirow[t]{2}{*}{388.509} & \multirow[t]{2}{*}{0.0} & \multirow[t]{2}{*}{388.509} & \multirow[t]{2}{*}{1.0} \\
\hline & & 4.499 & 24 & $0.187^{\mathrm{c}}$ & & & & \\
\hline
\end{tabular}

Dependent variable: concentration of extracted mangiferin

${ }^{\text {a }}$ Computed using alpha $=0.05$

b MS (Error)

c MS (TMIN) 

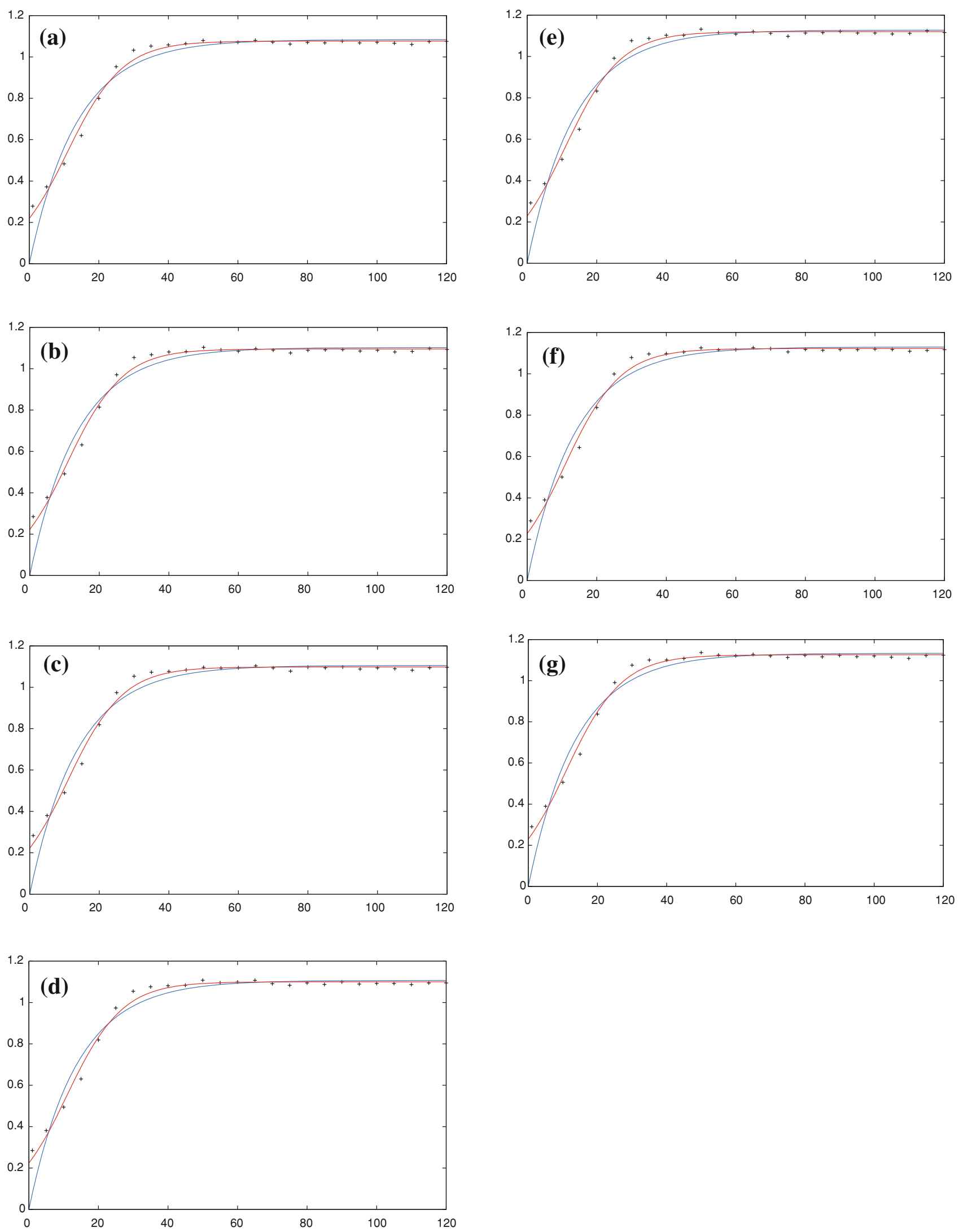
४Fig. 5 Temporal evolution of the effect of pre-leaching time (independent variable) on the yield of mangiferin content extracted from Curcuma amada at various experimental design points ( $x$ axis: time in $\mathrm{s} ; y$ axis: yield in $\mathrm{mg} / \mathrm{g}$ ). The experimental data (symbols) fitted to the 2-parameter model (Eq. 1, blue) and 3-parameter logistic model (Eq. 2, red) are shown in Fig. 5a-g for 1, 5, 10, 15, 20, 25 and 30 min respectively

matrix, allowing the dissolution of components to be extracted. The steep decrease in mangiferin content at $900 \mathrm{~W}$ is due to the rapid degradation of mangiferin at higher microwave power range. As the experiments are conducted in dry matter, as is usually the case (Mandal et al. 2007), chances of degradation due to drying or evaporation at a higher microwave power intensity are ruled out. Similar results of decrease in extraction yield of astragalosides from Radix astragali at high power due to disorderly molecular interactions have been reported in the optimization study of MAE of four main astragalosides in Radix astragali (Yan et al. 2010).

Results of a two-way ANOVA with extraction time and microwave power as independent variables are given in Table 1. The mangiferin content in Curcumaamada is significantly dependent on microwave power and extraction time as well as their interaction. Newman-Keuls test suggest that the mangiferin content is significant at $550 \mathrm{~W}$, validating our experimental results of extracting the highest mangiferin content at $550 \mathrm{~W}$ from Curcuma amada. Student's independent $t$ test further confirms that both microwave power and extraction time have a significant effect on the mangiferin content.

\section{Effect of extraction time}

As seen in Fig. 3, mangiferin content increases significantly with the increase in extraction time from 1 to $50 \mathrm{~s}$ before reaching a steady state. The mangiferin content of Curcuma amada kept in a pre-leaching time of $1 \mathrm{~min}$ and extracted at $550 \mathrm{~W}$ for $50 \mathrm{~s}$ is found to be maximum

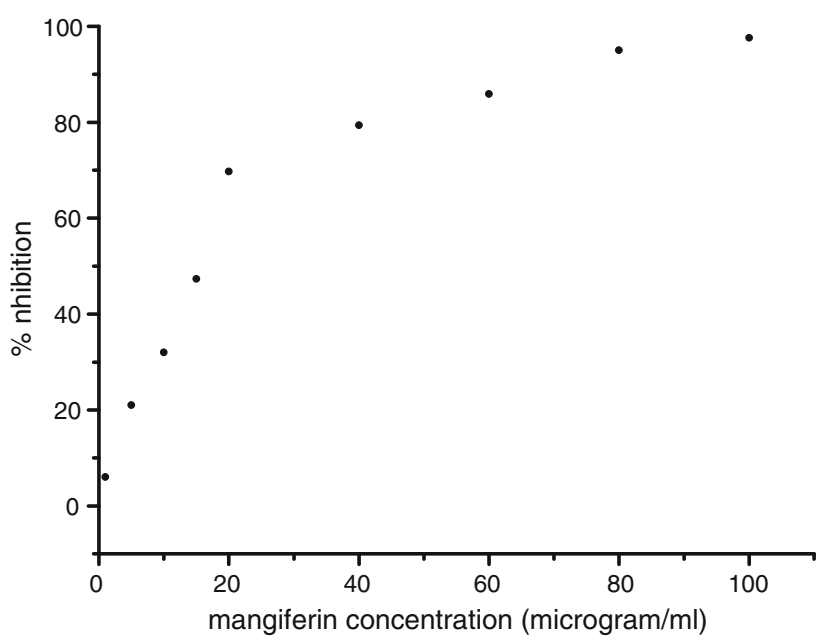

Fig. 6 DPPH radical scavenging activity of mangiferin obtained from microwave-assisted extraction of Curcuma amada at microwave power- $550 \mathrm{~W}$, pre-leaching time-20 min, extraction time- $50 \mathrm{~s}$ and ethanol concentration- $80 \%$

around $0.7121 \mathrm{mg} / \mathrm{g}$. Beyond $50 \mathrm{~s}$ of extraction time, no significant increase in mangiferin content is observed. Similar observations are also reported for MAE of artemisinin in from Artemisia аппиа (Pan et al. 2007) and tanshinones from Salvia Miltiorrhiza Bunge (Hao et al. 2002).

\section{Effect of solvent concentration}

Preliminary screening experiments (not reported in this study) with different organic extraction solvents such as acetone, acetonitrile, methanol and ethanol have been carried out and it was observed that ethanol yielded significant mangiferin content. Ethanol undergoes less microwave absorption than water due to its lower dielectric loss value but the overall heating efficiency for the solvent will remain higher than that of water due to increased value of the dissipation factor. Extraction with aqueous ethanol has been reported in earlier studies since it has less

Table 3 Test of between-subjects effects: a two-way analysis of variance with pre-leaching time and extraction time as independent factors

\begin{tabular}{|c|c|c|c|c|c|c|c|c|}
\hline Source & & $\begin{array}{l}\text { Type III sum } \\
\text { of squares }\end{array}$ & $d f$ & Mean square & $F$ & Sig. & $\begin{array}{l}\text { Noncent. } \\
\text { parameter }\end{array}$ & $\begin{array}{l}\text { Observed } \\
\text { power }^{\mathrm{a}}\end{array}$ \\
\hline \multirow[t]{2}{*}{ Pre-leaching time } & \multirow[t]{2}{*}{ Hypothesis error } & $3.711 \mathrm{E}-02$ & 6 & $6.186 \mathrm{E}-03$ & \multirow[t]{2}{*}{254.053} & \multirow[t]{2}{*}{0.0} & \multirow[t]{2}{*}{$1,524.317$} & \multirow[t]{2}{*}{1.0} \\
\hline & & $3.506 \mathrm{E}-03$ & 144 & $2.435 \mathrm{E}-05^{\mathrm{b}}$ & & & & \\
\hline \multirow[t]{2}{*}{ Extraction time } & \multirow[t]{2}{*}{ Hypothesis error } & 10.311 & 24 & 0.430 & \multirow[t]{2}{*}{$17,644.599$} & \multirow[t]{2}{*}{0.0} & \multirow[t]{2}{*}{$42,347.037$} & \multirow[t]{2}{*}{1.0} \\
\hline & & $3.506 \mathrm{E}-03$ & 144 & $2.435 \mathrm{E}-05^{\mathrm{b}}$ & & & & \\
\hline \multirow[t]{2}{*}{ Pre-leaching time $\times$ extraction time } & \multirow[t]{2}{*}{ Hypothesis error } & 166.914 & 1 & 166.914 & \multirow[t]{2}{*}{388.523} & \multirow[t]{2}{*}{0.0} & \multirow[t]{2}{*}{388.523} & \multirow[t]{2}{*}{1.0} \\
\hline & & 10.311 & 24 & $0.430^{\mathrm{c}}$ & & & & \\
\hline
\end{tabular}

Dependent variable: concentration of extracted mangiferin

${ }^{\text {a }}$ Computed using alpha $=0.05$

${ }^{\mathrm{b}} \mathrm{MS}$ (Error)

${ }^{\text {c }}$ MS (TMIN) 
Fig. 7 FTIR spectrum of mangiferin extracted from a Curcuma amada by MAE at $550 \mathrm{~W}$ and $\mathbf{b}$ mangiferin standard (for peak values refer Table 1)

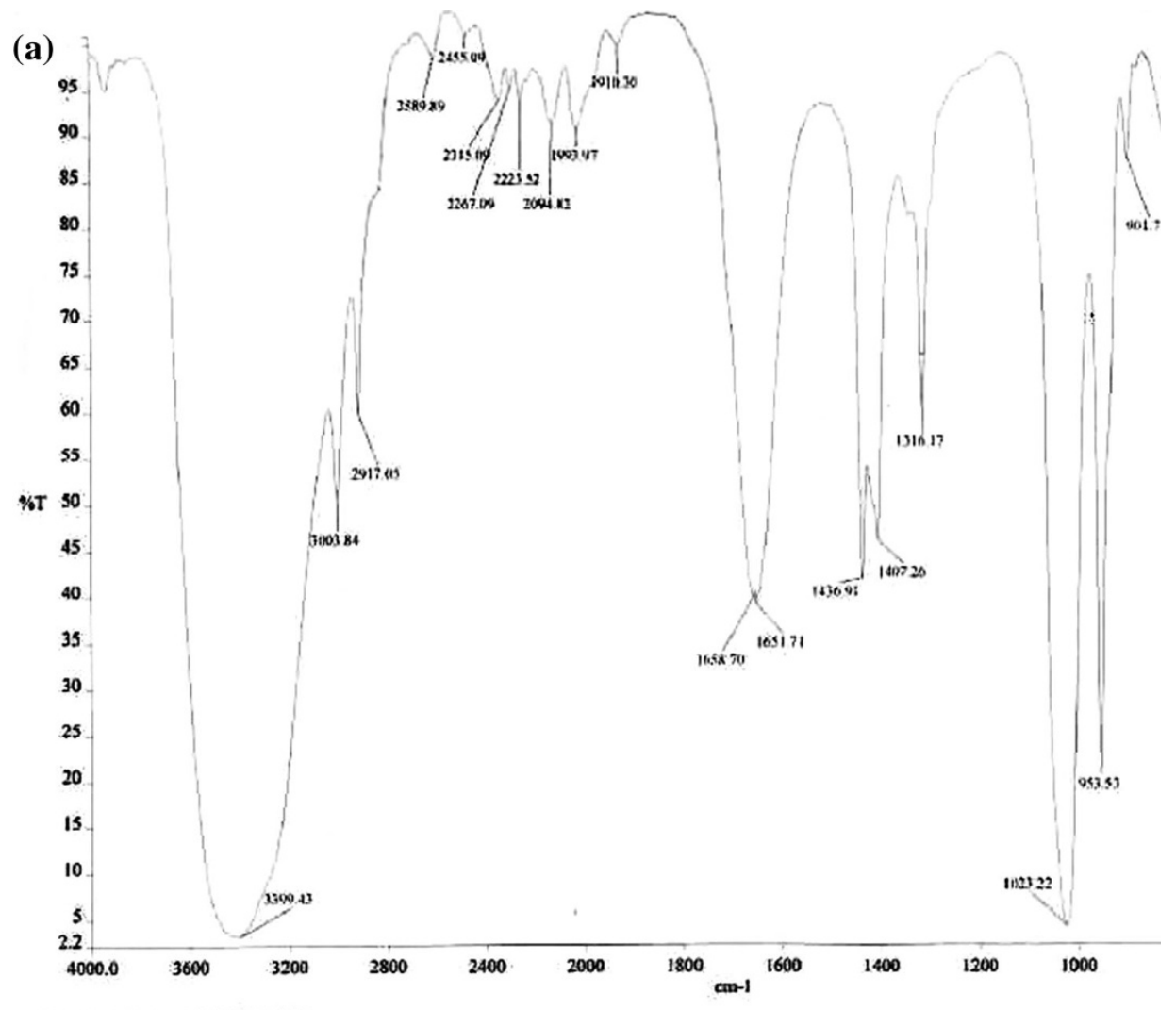

Spectrum Name: DMSO-1.002

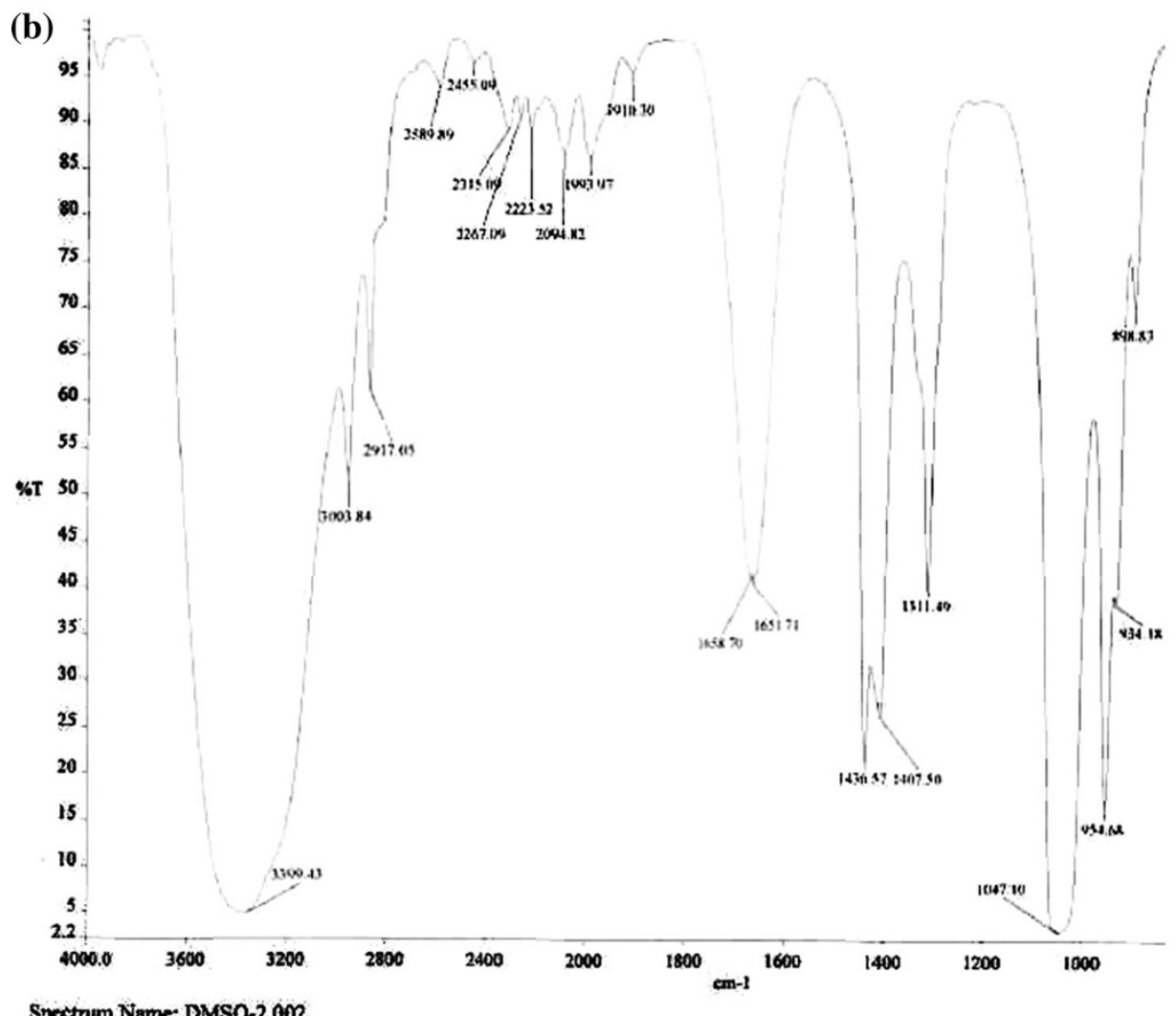


restrictions in food applications (Wardhani et al. 2010; Wang et al. 2010; Hemwimon et al. 2007). MAE of $2.5 \mathrm{~g}$ of dry Curcuma amada powder is carried out at microwave power of $550 \mathrm{~W}$, pre-leaching time of $1 \mathrm{~min}$ and irradiation time of 1-120 s with aqueous ethanol as solvent. The effect of aqueous ethanol concentration on mangiferin content can be seen in Fig. 4a-f. The mangiferin content increases significantly with increase in ethanol concentration up to $80 \%$ ethanol concentration; beyond $80 \%$ ethanol concentration there is a decrease in mangiferin content. Dhobi et al. (2009) found similar results in their work related to optimization of MAE of bioactive flavonolignan-silibinin. A maximum mangiferin content of $0.8864 \mathrm{mg} / \mathrm{g}$ is obtained in $80 \%$ ethanol concentration at extraction time of $50 \mathrm{~s}$. One possible reason for the

Table 4 FTIR peak values of mangiferin after microwave-assisted extraction at $550 \mathrm{~W}$ with standard mangiferin

\begin{tabular}{lll}
\hline $\begin{array}{l}\text { Functional } \\
\text { group }\end{array}$ & $\begin{array}{l}\text { Wave number }\left(\mathrm{cm}^{-1}\right) \text { mangiferin } \\
\text { extracted from Curcuma amada } \\
\text { by microwave-assisted extraction } \\
\text { at 550 W }\end{array}$ & $\begin{array}{l}\text { Wave number } \\
\left(\mathrm{cm}^{-1}\right) \text { mangiferin } \\
\text { standard }\end{array}$ \\
\hline $\mathrm{O}-\mathrm{H}$ & $3,399.43$ & $3,399.43$ \\
$\mathrm{C}-\mathrm{H}$ & $2,917.05$ & $2,917.05$ \\
$(>\mathrm{C}=\mathrm{O})$ & $1,658.70$ & $1,660.91$ \\
$\mathrm{C}=\mathrm{C}$ & $1,436.91$ & $1,436.57$ \\
$\mathrm{C}-\mathrm{O}$ & $1,316.17$ & $1,311.49$ \\
$\mathrm{C}-\mathrm{O}-\mathrm{C}$ & $1,023.22$ & 1,047 \\
\hline
\end{tabular}

increased efficiency with $80 \%$ ethanol might be due to the increase in swelling of plant material by presence of some amount of water, which increased the contact surface area between the plant matrix and the solvent. Presence of some amount of water can also increase the mass transfer process by increasing the relative polarity of the solvent, thus improving its solubilizing capacity. Similar results were reported by $\mathrm{Li}$ et al. (2004) during microwave-assisted solvent extraction and HPLC determination of effective constituents in Eucommia ulmoides Oliv.

Statistical results indicate that the mangiferin is positively correlated but insignificant with the ethanol concentration but significant with extraction time. The results of ANOVA are given in Table 2. Both the ethanol concentration and extraction time along with their interaction are significant with respect to the mangiferin content. Newman-Keuls test show that the mangiferin content is significant at higher ethanol concentration of 70, 80, 90 and $100 \%$ with ethanol concentration of $80 \%$ yielding the highest mangiferin content.

\section{Effect of pre-leaching time}

Figure 5a-g shows the effect of pre-leaching time on the yield of mangiferin content. Similar to Figs. 2a-e and 4a-f, the symbols represent the experimental data and the continuous curves represent the model fit. Pre-leaching time can be defined as the contact time between sample matrix and extracting solvent before microwave extraction. MAE
Table 5 Optimized parameter set using the two-parameter modified first order kinetic model (Eq. 1) and the corresponding statistical ratio of the experimental design points for the three independent variables: microwave power, ethanol concentration and preleaching time

\begin{tabular}{|c|c|c|c|c|}
\hline \multirow[t]{2}{*}{ Independent variables } & \multirow[t]{2}{*}{ Experimental design points } & \multicolumn{2}{|c|}{ Model parameters } & \multirow{2}{*}{$\begin{array}{l}\text { Statistical } \\
\text { indicator } \\
Y_{\mathrm{RMS}} / Y_{\max }(-)\end{array}$} \\
\hline & & $\overline{Y_{\max }(\mathrm{mg} / \mathrm{g})}$ & $\overline{k_{\mathrm{m}}\left(\mathrm{s}^{-1}\right)}$ & \\
\hline \multirow[t]{5}{*}{ Microwave power } & $250 \mathrm{~W}$ & 0.013715 & 0.094507 & 0.084504 \\
\hline & $350 \mathrm{~W}$ & 0.568469 & 0.069558 & 0.018957 \\
\hline & $450 \mathrm{~W}$ & 0.622861 & 0.069927 & 0.018408 \\
\hline & $500 \mathrm{~W}$ & 0.643451 & 0.065034 & 0.051907 \\
\hline & $550 \mathrm{~W}$ & 0.718277 & 0.073040 & 0.052717 \\
\hline \multirow[t]{6}{*}{ Ethanol concentration } & $50 \%$ & 0.754853 & 0.073097 & 0.052993 \\
\hline & $60 \%$ & 0.761361 & 0.072713 & 0.052911 \\
\hline & $70 \%$ & 0.804594 & 0.072975 & 0.052548 \\
\hline & $80 \%$ & 0.890682 & 0.073307 & 0.052608 \\
\hline & $90 \%$ & 0.831694 & 0.073287 & 0.053215 \\
\hline & $100 \%$ & 0.718277 & 0.073040 & 0.052717 \\
\hline \multirow[t]{7}{*}{ Pre-leaching time } & $1 \mathrm{~min}$ & 1.083663 & 0.072867 & 0.052288 \\
\hline & $5 \mathrm{~min}$ & 1.102309 & 0.073028 & 0.052639 \\
\hline & $10 \min$ & 1.105546 & 0.072777 & 0.052213 \\
\hline & $15 \mathrm{~min}$ & 1.107016 & 0.072974 & 0.052566 \\
\hline & $20 \min$ & 1.127495 & 0.072855 & 0.052249 \\
\hline & $25 \mathrm{~min}$ & 1.129510 & 0.072919 & 0.052386 \\
\hline & $30 \mathrm{~min}$ & 1.133223 & 0.072485 & 0.052057 \\
\hline
\end{tabular}


Table 6 Optimized parameter set using the three-parameter delayed logistic model (Eq. 2) and the corresponding statistical ratio of the experimental design points for the three independent variables: microwave power, ethanol concentration and preleaching time

\begin{tabular}{llllll}
\hline $\begin{array}{l}\text { Independent } \\
\text { variables }\end{array}$ & $\begin{array}{l}\text { Experimental } \\
\text { design points }\end{array}$ & \multicolumn{2}{l}{ Model parameters } & $\begin{array}{l}\text { Statistical } \\
\text { indicator } \\
Y_{\text {RMS }} / Y_{\max }(-)\end{array}$ \\
\cline { 3 - 6 } Microwave power & $250 \mathrm{~W}$ & 0.013716 & 0.013716 & 9.078383 & 0.064274 \\
& $350 \mathrm{~W}$ & 0.558402 & 0.156855 & 11.625592 & 0.040377 \\
& $450 \mathrm{~W}$ & 0.611637 & 0.158482 & 11.513974 & 0.040776 \\
& $500 \mathrm{~W}$ & 0.636598 & 0.121393 & 12.340408 & 0.023855 \\
& $550 \mathrm{~W}$ & 0.713695 & 0.125821 & 10.917342 & 0.021411 \\
Ethanol concentration & $50 \%$ & 0.749934 & 0.126824 & 10.938109 & 0.022006 \\
& $60 \%$ & 0.756452 & 0.125319 & 10.96249 & 0.021600 \\
& $70 \%$ & 0.799469 & 0.125387 & 10.909826 & 0.021116 \\
& $80 \%$ & 0.885108 & 0.126128 & 10.886925 & 0.021164 \\
& $90 \%$ & 0.826444 & 0.126240 & 10.88443 & 0.021859 \\
& $100 \%$ & 0.713695 & 0.125821 & 10.917342 & 0.021411 \\
& $1 \mathrm{~min}$ & 1.076805 & 0.125075 & 10.928752 & 0.020460 \\
& $5 \mathrm{~min}$ & 1.095355 & 0.125485 & 10.911725 & 0.020907 \\
& $10 \mathrm{~min}$ & 1.098343 & 0.125436 & 10.941557 & 0.020672 \\
& $15 \mathrm{~min}$ & 1.100119 & 0.125104 & 10.919032 & 0.020930 \\
& $20 \mathrm{~min}$ & 1.120260 & 0.124949 & 10.905220 & 0.020455 \\
& $25 \mathrm{~min}$ & 1.122212 & 0.125592 & 10.921825 & 0.021031 \\
& $30 \mathrm{~min}$ & 1.126029 & 0.124124 & 10.972533 & 0.020265 \\
\hline & & & & &
\end{tabular}

Fig. 8 Temporal evolution of yield on microwave power during the extraction process (in accordance with a modified logistic expression; see Eq. 3) for all the design points used in the experimental setup

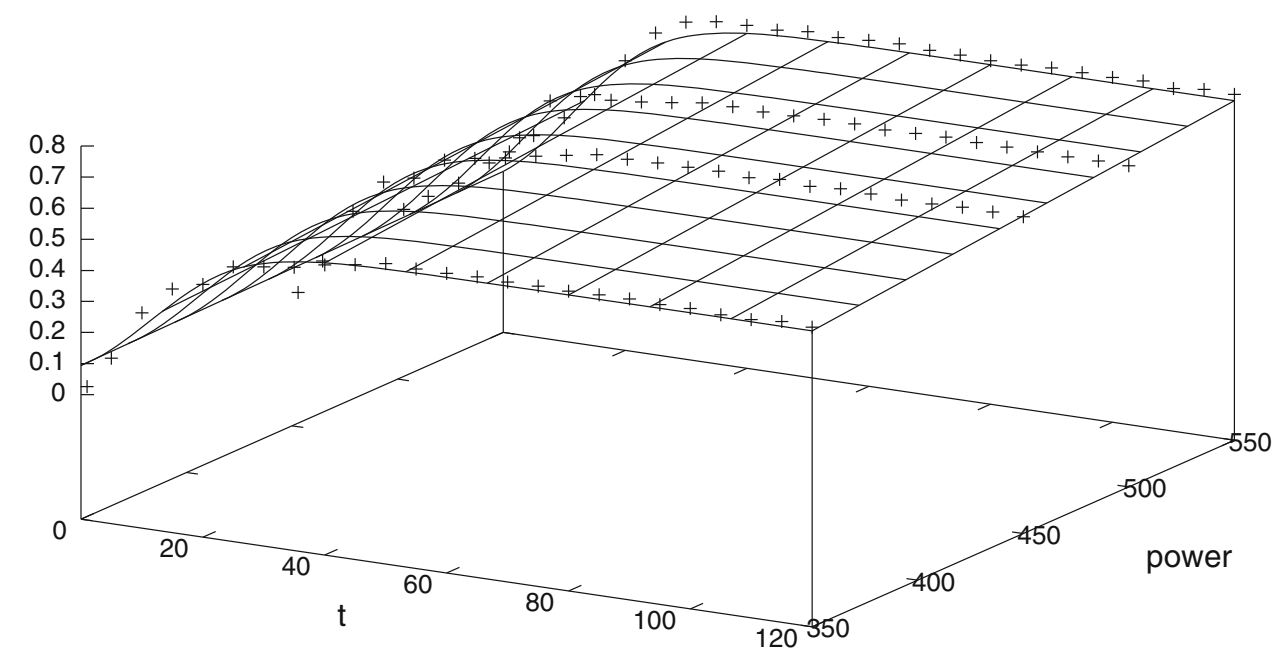

of $2.5 \mathrm{~g}$ of dry Curcuma amada powder is carried out at microwave power of $550 \mathrm{~W}, 80 \%$ ethanol concentration and irradiation time of $1-120 \mathrm{~s}$ for different pre-leaching time of 1-30 min. It is observed from these figures that with an increase in pre-leaching time from 1 to $20 \mathrm{~min}$, there is an increase in mangiferin content. Beyond a preleaching time of $20 \mathrm{~min}$, there is no noticeable increase in the yield of mangiferin content. It can be inferred that pre-leaching time of 20 min allows sufficient swelling of the plant matrix. This increased hydrated status of plant material helps in the bursting of the cell wall due to internal thermal stress and enlargement of the cellular pores, thus facilitating leaching of the target analyte. The results for ANOVA for pre-leaching time and extraction time as independent factors are given in Table 3. The Newman-Keuls test indicates that the pre-leaching time is not a significant factor contributing to the mangiferin content.

Figure 6 shows the DPPH radical scavenging activity of mangiferin extracted from Curcuma amada by MAE at the optimal condition of microwave power $550 \mathrm{~W}$, pre-leaching time $20 \mathrm{~min}$, extraction time $50 \mathrm{~s}$ and ethanol 
Fig. 9 Temporal evolution of yield on the ethanol concentration during the extraction process (in accordance with a modified logistic expression; see Eq. 3) for all the design points used in the experimental setup

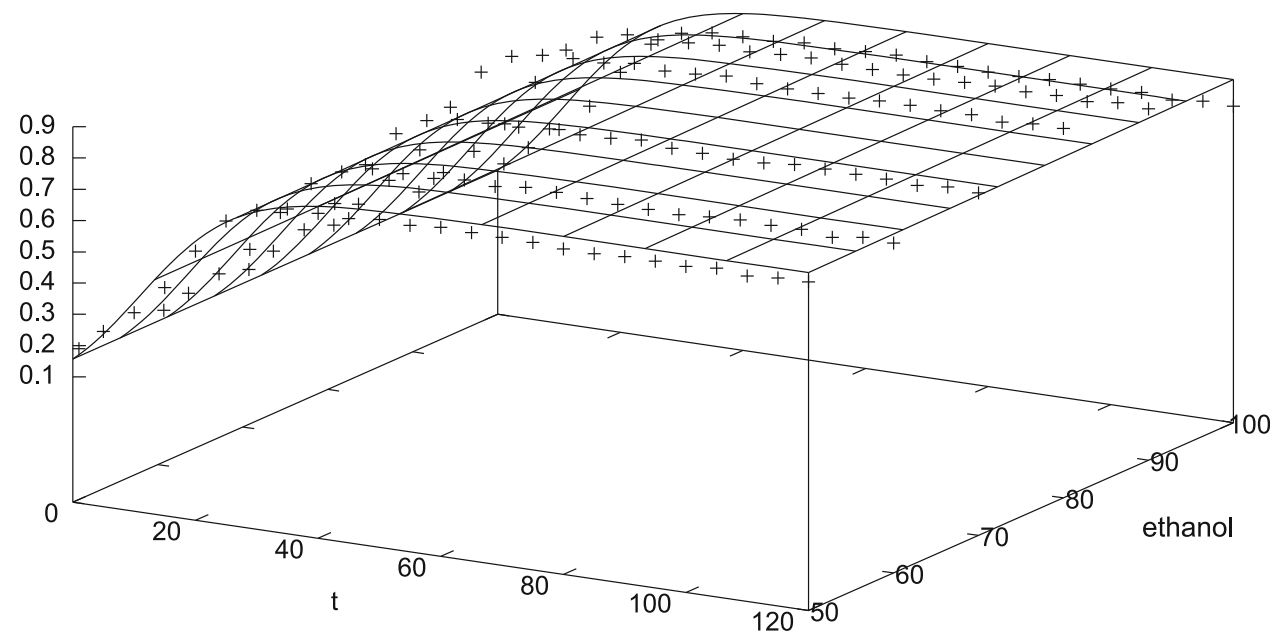

concentration $80 \%$. It is observed that the IC50 value for mangiferin extracted from Curcuma amada was $17.04 \mu \mathrm{g} /$ $\mathrm{ml}$ and the radical scavenging activity was directly proportional to the concentration of mangiferin with an inhibition of $97.65 \%$ at $100 \mu \mathrm{g} / \mathrm{ml}$. From this observation, it is clear that mangiferin obtained from MAE at $550 \mathrm{~W}$, preleaching time of $20 \mathrm{~min}$, extraction time of $50 \mathrm{~s}$ and $80 \%$ ethanol concentration retained its antioxidant property. It is important to note here that Stoilova et al. (2005) had earlier established the antioxidant properties of mangiferin standard using DPPH radical scavenging activity of mangiferin.

FTIR analysis has proven to be a valuable tool for the characterization and identification of compounds or functional groups (chemical bonds) present in an unknown mixture of plant extracts (Eberhardt et al. 2007; Hazra et al. 2007). Figure 7 shows the FTIR spectrum of mangiferin extracted from Curcuma amada by MAE at $550 \mathrm{~W}$ and mangiferin standard. Six functional groups were identified: FTIR spectrum results of mangiferin after MAE showed peaks at $3,399 \mathrm{~cm}^{-1}$ and indicated the presence of secondary $\mathrm{OH}^{-}$bond, peak at $2,917 \mathrm{~cm}^{-1}$ showed the presence of $\mathrm{C}-\mathrm{H}$ anti-symmetric stretching, peak at $1,658.70 \mathrm{~cm}^{-1}$ indicated the presence $\mathrm{C}-\mathrm{O}$ stretching, peak at $1,436.91 \mathrm{~cm}^{-1}$ indicated the presence of $\mathrm{CH}-\mathrm{CH}$ bending and peak at $1,316.17 \mathrm{~cm}^{-1}$ indicated the presence of $\mathrm{C}-\mathrm{O}$ bond. Peak at $1,023.22 \mathrm{~cm}^{-1}$ showed the presence of $\mathrm{C}-\mathrm{C}$ stretching in the mangiferin structure. Comparing the FTIR analysis of mangiferin extracted by MAE and mangiferin standard (see Table 4) revealed the similarity and variation in the functional group. The absorption spectra showed that the $\mathrm{C}-\mathrm{O}$ bond and $\mathrm{C}-\mathrm{O}-\mathrm{C}$ stretching of the mangiferin were affected during the extraction process.

The results of the validation using the two-parameter first-order kinetic model (Eq. 1) and using the threeparameter logistic model (Eq. 2) for microwave power (Fig. 2a-e), ethanol concentration (Fig. 4a-f) and pre- leaching time (Fig. 5a-g) are shown, respectively. As the response for $900 \mathrm{~W}$ was found to vary widely from the initial five responses (i.e. 250, 350, 450, 500 and $550 \mathrm{~W}$ ) and did not follow a clear sequence, it was neglected while validating the kinetic model for microwave power with extraction time. To check the goodness of fit, the ratio of the root mean square (RMS) value to the maximum (limit) value of mangiferin content is considered. The optimized parameter set and the corresponding value of the statistical indicator $Y_{\mathrm{RMS}} / Y_{\max }$ are summarized in Tables 5 and 6. The goodness of fit statistical indicator helps to determine how well the curve fits the data. The curve fits (based on Eq. 3) of the temporal evolution of yield on microwave power and ethanol concentration are shown in Figs. 8 and 9 , respectively. The best-fit parameter values for $\left(P_{\text {ref }}, k_{\mathrm{m}}\right.$, $\tau)$ are found to be $(759.42,0.14,11.68)$ and $(2,315.22,0.13$, 10.91) using the NLLS Marquardt-Levenberg algorithm. The corresponding indicator $Y_{\mathrm{RMS}} / Y_{\max }$ equals 0.054598 and 0.070991 , respectively, for microwave power and ethanol concentration, indicating a good fit.

\section{Conclusions}

Mangiferin was extracted from Curcuma amada using microwave-assisted extraction technique. Maximum mangiferin content of $1.1156 \mathrm{mg} / \mathrm{g}$ was obtained at microwave power of $550 \mathrm{~W}$ and extraction time of $50 \mathrm{~s}$ with $80 \%$ ethanol as a solvent and pre-leaching time of $20 \mathrm{~min}$ and retained its antioxidant properties. The experimental profiles fitted into a two-parameter modified firstorder kinetic model and a three-parameter modified logistic model with sufficient accuracy. The MAE of mangiferin from Curcuma amada using ethanol can be safely employed in food and medicinal industries as it is not only efficient from the industrial point of view, but also ecofriendly since it prevents environmental hazards. This 
indicates the usefulness and significance of MAE as a novel extraction technique in biotechnological applications.

Conflict of interest The authors declare that they have no conflict of interest.

Open Access This article is distributed under the terms of the Creative Commons Attribution License which permits any use, distribution, and reproduction in any medium, provided the original author(s) and the source are credited.

\section{References}

Ara N, Nur H (2009) In Vitro antioxidant activity of methanolic leaves and flowers extracts of Lippia alba. Res J Med Med Sci 4:107-110

Camel V (2000) Microwave-assisted solvent extraction of environmental samples. TrAC Trends Anal Chem 19:229-248

Dean JR (2010) Extraction techniques in analytical sciences. Wiley, New York, pp 167-183

Dhobi M, Mandal V, Hemalatha S (2009) Optimization of microwave-assisted extraction of bioactive flavonolignan-silybinin. J Chem Metrol 3:13-23

Eberhardt TL, Li X, Shupe TF, Hse CY (2007) Chinese tallow tree (Sapium sebiferum) utilization: characterization of extractives and cell-wall chemistry. Wood Fiber Sci 39:319-324

Ferguson P, Harding M, Young J (2012) Green analytical chemistry. In: Zhang W, Cue BW (eds) Green techniques for organic synthesis and medicinal chemistry. Wiley, Chichester

Hao JY, Han W, Huang S, Xue BY (2002) Microwave-assisted extraction of artemisinin from Artemisia annua L. Sep Purif Technol 28:191-196

Hazra KM, Roy RN, Sen SK, Laska S (2007) Isolation of antibacterial pentahydroxy flavones from the seeds of Mimusops elengi Linn. Afr J Biotechnol 6:1446-1449

Hemwimon S, Pavasant P, Shotipru A (2007) Microwave-assisted extraction of antioxidative anthraquinones from roots of $\mathrm{Mo}$ rinda citrifolia. Sep Purif Technol 54:44-50

Huie CW (2002) A review of modern sample preparation techniques for the extraction and analysis of medicinal plants. Anal Bioanal Chem 373:23-30

Jatoi SA, Kikuchi A, Gilani SA, Watanabe KN (2007) Phytochemical, pharmacological and ethnobotanical studies in mango ginger (Curcuma amada Roxb.; Zingiberaceae). Phytother Res 21:507-516

Joubert E, Manley M, Botha M (2008) Evaluation of spectrophotometric methods for screening of green rooibos (Aspalathus linearis) and green honeybush (Cyclopia genistoides) extracts for high levels of bio-active compounds. Phytochem Anal 19:169-178

Li H, Bo C, Zhang ZH, Yao SZ (2004) Focused microwave-assisted solvent extraction and HPLC determination of effective constituents in Eucommia ulmoides Oliv. (E. ulmoides). Talanta 63:659-665

Mandal V, Mohan Y, Hemalatha S (2007) Microwave-assisted extraction-an innovative and promising extraction tool for medicinal plant research. Pharmacogn Rev 1:7-18

Morgan SL, Deming SN (1974) Simplex optimization of analytical chemistry methods. Anal Chem 46:1170-1181

Muruganandan S, Gupta S, Kataria M, Lal J, Gupta PK (2002) Mangiferin protects the streptozotocin-induced oxidative damage to cardiac and renal tissues in rats. Toxicology 176:165-173

Omenn GS, Goodmann GE, Thornquist MD, Balmes J (1996) Effects of a combination of beta-carotene and vitamin A on lung cancer and cardiovascular disease. N Engl J Med 334:1150-1155

Padmapriya K, Dutta A, Chaudhuri S, Dutta D (2012) Microwaveassisted extraction of mangiferin from Curcuma amada. 3Biotech 2:27-30

Pan X, Niu G, Liu H (2007) Microwave-assisted extraction of tanshinones from Salvia miltiorrhiza Bunge with analysis by high-performance liquid chromatography. J Chromatogr A 922:371-375

Qu X, Wu CFJ (2005) One-factor-at-a-time designs of resolution V. J Stat Plan Inference 131:407-416

Romanik G, Gilgenast E, Przyjazny A, Namiesnik J (2007) Techniques of preparing plant material for chromatographic separation and analysis. Biochem Biophys Methods 70:253-261

Sasikumar B (2005) Genetic resources of Curcuma: diversity, characterization and utilization. Plant Genet Resour Charact Util 3:230-251

Shankaracharya NB (1982) Mango ginger. Indian Cocoa Arecanut Spices J 5:78-80

Singh S, Kumar JK, Saikia D, Shanker K (2010) A bioactive labdane diterpenoid from Curcuma amada and its semisynthetic analogues as antitubercular agents. Eur J Med Chem 45:4379-4382

Stoilova I, Gargova S, Stoyanova A, Ho L (2005) Antimicrobial and antioxidant activity of the polyphenol mangiferin. Herba Polonica 51:37-44

Wang YL, Xi GS, Zheng YC, Miao FS (2010) Microwave-assisted extraction of flavonoids from Chinese herb Radix puerariae $(G e$ Gen). J Med Plant Res 4:304-308

Wardhani DH, Vázquez JA, Pandiella SS (2010) Optimisation of antioxidants extraction from soybeans fermented by Aspergillus oryzae. Food Chem 118:731-739

Yan MM, Liu W, Fu YJ, Zu YG (2010) Optimisation of the microwave-assisted extraction process for four main astragalosides in Radix astragali. Food Chem 119:1663-1670

Yukalov VI, Yukalova EP, Sornette D (2009) Punctuated evolution due to delayed carrying capacity. Physica D 238:1752-1767 